\title{
Weed Suppression by Common Buckwheat: A Review
}

\author{
Benoît Falquet, Aurélie Gfeller, Mickaël Pourcelot, Frédéric Tschuy and Judith Wirth
}

Agroscope, Nyon, Switzerland

(Received January 21, 2014; Accepted December 6, 2014)

\begin{abstract}
Common buckwheat (Fagopyrum esculentum) is well known for its weed-suppressive ability. This property is probably due to multiple factors such as resource competition, allelopathy and soil property modifications. A better understanding of the mechanisms of weed suppression could improve the development of new strategies for weed management using cover crops. In this review, the different factors that could be potentially responsible for weed suppression by common buckwheat are discussed. Special emphasis is put on the role of allelopathy.
\end{abstract}

Keywords : allelopathy, Fagopyrum esculentum, resource competition, weed suppression

\section{INTRODUCTION}

In a context of growing public concern about the detrimental effect of herbicides on human health and the environment, the development of a more sustainable agriculture and cost-effective techniques for weed control become a pressing need. Weeds are a nuisance in agro-ecosystems as they interfere with crop production. It is estimated that they produce a high potential loss of $34 \%$ (Oerke, 2006). The intensive use of herbicides is characterized by the presence of synthetic agrochemical residues in the environment and the development of weed resistance, making farming ecologically unsustainable. Sustainable agro-ecosystems should promote the efficient production of safe, high quality agricultural products, all while protecting and improving the natural environment. The use of cover crops may provide a pertinent answer to this challenge, because of their beneficial properties such as soil quality enhancement, protection against soil erosion, supply of nitrogen $(\mathrm{N})$ to subsequent crops and improvement in nutrient cycling as well as impacts on pest and weed management (Kumar et al., 2008). Many cover crops are known to successfully suppress weeds both during growth and after incorporation into the soil (Teasdale, 1996; Bhowmik and Inderjit, 2003). One of these cover crops is common buckwheat (Fagopyrum esculentum), a member of the Polygonaceae family. Its short life cycle and fast decomposition make it a good choice for a cover crop integrated in the crop rotation. For centuries, farmers have used the empirically known ability of buckwheat to suppress weeds (Tominaga and Uezu, 1995; Hayashi, 1998; Kalinova et al., 2005) and its cultivation is a widespread weed management technique in crop rotations and traditional agricultural systems (Khanh et al., 2005; Ohsawa and Nakatani, 2005). However, although during the past decades, the weed suppressive activity of common buckwheat has drawn a lot of attention, the mechanisms responsible for this effect have not yet been clearly identified. Several studies reported that weed biomass on fields where buckwheat is cultivated is considerably reduced compared to bare soil with big differences between weed species (Tominaga and Uezu, 1995; Kalinova, 2004; Kumar et al., 2009a). Weed suppression in growing plant stands can be due to resource competition for light, nutrients and water and/or to the release of allelopathic compounds into the soil environment as root exudates, foliar leachates, decomposition of residues or volatile compounds (Fig. 1A). Allelopathy has been defined as any direct or indirect harmful or beneficial effect by one plant on another through production of chemical compounds that escape into the environment (Rice, 1984). Besides strong weed suppression in growing buckwheat stands, it is known that incorporated buckwheat residues also suppress weeds (Tsuzuki and Dong, 2003; Xuan and Tsuzuki, 2004; Kumar et al., 2009a). To the best of our knowledge, there are no published field experimental data concentrating specifically on the weed suppressive effect caused by non-incorporated buckwheat residues (mulches). For other cover crops like hairy vetch (Vicia villosa) and rye (Secale cereale), the weed suppressive effect was considered predominantly caused by the creation of a physical barrier depriving weeds of light and a change in soil thermal regime (Liebman and Davis, 2000; Teasdale and Mohler, 2000). Moreover, it has been shown that mulch tended to positively influence growth and yield of the subsequent culture by increasing soil organic matter and moisture content and decreasing soil density and strength in a dose dependent matter (Pervaiz et al., 2009; Fig. 1B).

Weed suppression can be effective through changes in weed emergence, biomass, seed set and seed bank (Liebman and Davis, 2000; Fig. 1). However weed suppression, especially under field conditions, is due to a combination of several interactions. In order to develop new successful weed management strategies it is important to

Corresponding author: Judith Wirth, fax: $+41-22-363-13-25$, e-mail : judith.wirth@agroscope.admin.ch 


\section{A during cultivation}

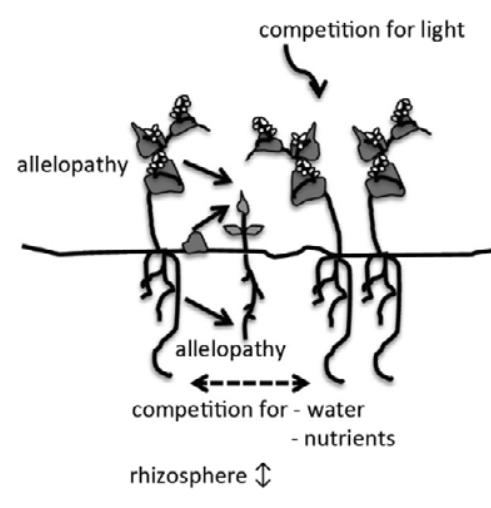

B mulch cover

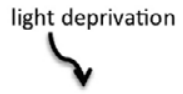

\section{$C$ residue incorporation}

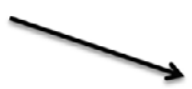

rhizosphere $\uparrow$

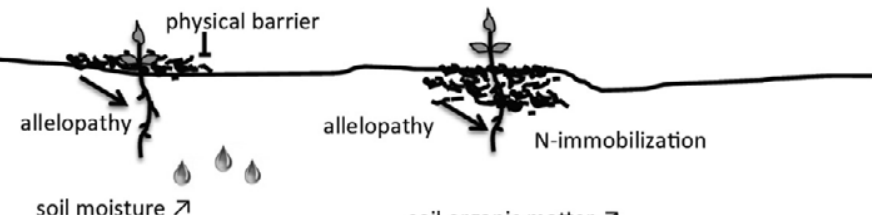

soil moisture $\lambda$

soil temperature $\downarrow$

soil organic matter $\lambda$

rhizosphere $\uparrow$

Effect on weeds: emergence, biomass, seed set, seed bank

Fig. 1 Possible causes for weed suppression by buckwheat during cultivation (A), mulch cover (B) and after incorporation (C). A buckwheat cover crop can help to control weeds by affecting their emergence, biomass, seed set and the seed bank in the soil. During cultivation (A) weed suppression might be due to resource competition for light, water and nutrients and/or allelopathic interactions due to root exudates, foliar leachates and decomposition of residues. A mulch cover (B) prevents seedlings from emerging by creating a physical barrier depriving weeds of light. It also has an influence on soil organic matter, moisture content and soil temperature. Moreover, allelopathic compounds may be leached into the soil. When residues are incorporated (C) soil organic matter increases and $\mathrm{N}$-immobilization might occur depending on the amount of added biomass. Furthermore allelochemicals might be released during litter decomposition. In all cases (A, B, C) the rhizosphere soil microbiota might have implications on the belowground allelopathic interactions.

assess and to understand the role of each of these suppressive effects individually.

\section{RESOURCE COMPETITION}

Some authors claim that the competition for light is responsible for the major part of weed suppression (Bicksler and Masiunas, 2009) by buckwheat, because it quickly establishes a thick canopy that prevents weeds from receiving enough light and therefore acts as a good competitor. However, there is no experimental proof for this hypothesis so far. Recently it has been shown in a pot trial that shading plays a decisive role in redroot pigweed (Amaranthus retroflexus) growth suppression by buckwheat, but that it is not the only factor (Falquet et al., 2014). In a study carried out in Switzerland a relation between the percentage of soil cover by different legume crops and weed biomass could be demonstrated. The authors showed that the ability of legumes to compete with weeds is closely correlated with the amount of biomass produced, i.e. the amount of shading (Gebhard et al., 2013). It is noteworthy that in another field trial weed density in a buckwheat plot seemed unaffected, while hairy galinsoga (Galinsoga ciliata) dry weight (DW) and seed production were reduced by $90 \%$ and $99 \%$ respectively (Kumar et al., 2009a). The same observation was made by Iqbal et al. (2003) who observed a constant number of weed plants in buckwheat plots compared to bare soil while weed DW was reduced by $75 \%$.

So far no studies have been published examining the capacity of buckwheat for water uptake, but this cover crop is known to be rather intolerant to drought (Creamer and Baldwin, 2000). It therefore probably suffers from water depletion before most surrounding weeds.

Competition for nutrients has only been examined in very few studies and no concluding explication can be given. In a greenhouse experiment powell amaranth (Amaranthus powellii) was grown in two types of sieved soil: bare soil and soil in which buckwheat had been cultivated for $35 \mathrm{~d}$. On the amended soil powell amaranth growth was reduced by $77 \%$ compared to the bare soil, while emergence remained unchanged (Kumar et al., 2009b). This observation supports the idea that nutrient tieup is responsible for weed growth suppression as less nutrients are available in the soil after buckwheat growth. However, no soil analysis for nutrients was carried out to confirm this hypothesis. In field experiments, it was observed that there are substantial differences in plant available $\mathrm{N}$ content between soil types and that $\mathrm{N}$ content is significantly reduced after buckwheat growth compared to bare soil (Kumar et al., 2008; 2009b), which also supports the above mentioned hypothesis. In another field trial, it was observed that weeding the buckwheat plots did not increase crop yield (Van Ryswyk et al., 2004). This suggests that weeds and buckwheat do not strongly compete for nutrients. Moreover, further field trials were conducted in fertilized fields where nutrient tie-up is unlikely to have occurred. Nevertheless, an important reduction of weed biomass by growing buckwheat was observed (Tominaga and Uezu, 1995; Kumar et al., 2009a). Buckwheat is able to extract phosphate from sources that are not available to other species. For this reason this might not be a competition advantage but rather a capacity for buckwheat to grow where other plants cannot (Zhu et al., 2002).

When buckwheat residues are additionally 
incorporated into the soil $\mathrm{N}$-immobilization might occur as a supplementary factor that leads to N-deficiency and thus supplementary growth reduction (Fig. 1C). Nimmobilization is a factor frequently quoted to explain weed suppression by crop residues (Kumar et al., 2008). When a large quantity of organic carbon is provided to the soil microorganisms, microbial activity is stimulated and the available $\mathrm{N}$ in the soil is consumed. This process called "N immobilization" occurs when plant residues with a high $\mathrm{C}: \mathrm{N}$ ratio are incorporated into the soil. Depending on the sources, a C:N ratio comprised between 20 and 30 is considered the threshold between net mineralization and $\mathrm{N}$ immobilization in the soil by microorganisms (Kaye and Hart, 1997; Kumar et al., 2009a). The consecutive temporary reduction in the amount of plant available $\mathrm{N}$ may impact weed emergence and growth. In the case of buckwheat, $\mathrm{N}$ tie-up caused by immobilization is unlikely, as according to the literature buckwheat residues have a rather low $\mathrm{C}: \mathrm{N}$ ratio ranging from 21 in $64 \mathrm{~d}$ old plants (Creamer and Baldwin, 2000) to 8.5 in $42 \mathrm{~d}$ old plants (Kumar et al., 2009a). However several experiments performed by Kumar et al. (2008; 2009a; 2009b; 2011) suggested that $\mathrm{N}$-immobilization might affect weed biomass. It is important to know, that the timing of nutrient availability in relation to crop and weed needs appears to be especially important for determining the outcome of competitive interaction (Liebman and Davis, 2000).

\section{ALLELOPATHY}

\section{Allelopathic compounds released by roots}

Kalinova et al. (2005) showed that during germination and early development of buckwheat, several allelopathic compounds are exudated. With a simple in vitro experiment they demonstrated that germinating buckwheat achenes reduced the root and shoot elongation of lettuce (Lactuca sativa), garden cress (Lepidium sativum), timothygrass (Phleum pratense) and italian ryegrass (Lolium multiflorum). Moreover, culture solution in which buckwheat was grown for $10 \mathrm{~d}$ exhibited a dose-response suppressive activity on root and hypocotyl elongation of lettuce seedlings (Kato-Noguchi et al., 2007). Caprolactam (azepan-2-one) is one of the molecules responsible for this inhibition. In fact, cress radicle growth is inhibited at a concentration of $3 \mu \mathrm{g} \mathrm{ml}^{-1}$ which corresponds to 25 buckwheat seeds (Tin et al., 2009).

Even though the existence of allelopathic interactions during the early stages of buckwheat growth is established, the exudation of phytotoxic molecules during the later development of this plant is not clearly demonstrated. Based on the measurement of the niche differentiation value in field conditions, it was concluded that allelopathy is not a mechanism by which buckwheat suppresses canada thistle (Eskelsen and Crabtree, 1995). However, Falquet et al. (2014) could show that allelopathic root interactions are likely to play an important role in redroot pigweed growth suppression. Water extracts from buckwheat grown soil showed significant repressive activity on root elongation of barnyardgrass (Echinochloa crus-galli) and common purslane (Portulaca oleracea), whereas hairy galinsoga, livid amaranth and lettuce remained unaffected (Tominaga and Uezu, 1995; Kalinova et al., 2005). In another study (Kalinova et al., 2007), soil from a buckwheat stand showed significant suppressive activity against lettuce radicle elongation after $3 \mathrm{~d}$. In methanol and boiling water extracts of this soil, several phytotoxic molecules such as a gallic acid derivative, palmitic acid methyl ester, vanillic acid, rutin, and a 4-hydroxyacetophenone derivative were identified. However, it is unclear whether these compounds originated from root exudates, leachates or necrotic parts of buckwheat. The authors addressed this problem by analyzing agar medium where buckwheat was grown for $12 \mathrm{~d}$. A quercetin derivative, palmitic acid, squalene, epicatechin, vitexin and the same gallic acid derivative present in the soil extract were identified. Squalene, vitexine and an undefined enantiomer of epicatechin were present only in the agar medium and were probably exudated during the early stages of buckwheat growth. Among the identified exudated compounds, only palmitic acid and gallic acid were shown to be phytotoxic (Table 1; Tsuzuki et al., 1987; Golisz et al., 2007; Kalinova et al., 2007). Quercetin showed no inhibitory effect against the development of sev-

Table 1 Allelochemicals present in buckwheat tissues.

\begin{tabular}{|c|c|c|}
\hline allelochemical & class & $\mathrm{EC}_{50}{ }^{\mathrm{z}}\left(\mathrm{mg} \mathrm{kg}^{-1}\right)$ \\
\hline$(-)$-epicatechin & flavonoid & 65 (Golisz et al., 2007) \\
\hline$(+)$-catechin & flavonoid & 32 (Iqbal et al., 2003) -92 (Golisz et al., 2007) \\
\hline 2-piperidinemethanol & alkaloid & $<10$ (Iqbal et al., 2002) \\
\hline 4-piperidone & alkaloid & 50 (Iqbal et al., 2002) \\
\hline arachidic $\operatorname{acid}^{y}$ & fatty acid & $>250^{\times}$(Tsuzuki et al., 1987) \\
\hline behenic $\operatorname{acid}^{y}$ & fatty acid & $>250^{x}$ (Tsuzuki et al., 1987) \\
\hline caffeic acid & phenolic acid & 44 (Golisz et al., 2007) \\
\hline chlorogenic acid & phenolic acid & 86 (Golisz et al., 2007) \\
\hline fagomine & alkaloide & 10 (Iqbal et al., 2002) \\
\hline ferulic acid & phenolic acid & 48 (Golisz et al., 2007) \\
\hline gallic acid & phenolic acid & 38 (Golisz et al., 2007) - 23 (Kalinova et al., 2007) \\
\hline palmitic acid ${ }^{y}$ & fatty acid & $>250^{x}$ (Tsuzuki et al., 1987) \\
\hline quercetin & flavonoid & 734 (Golisz et al., 2007) \\
\hline rutin & flavonoid & 88 (Golisz et al., 2007) \\
\hline stearic acid & fatty acid & $>250^{x}$ (Tsuzuki et al., 1987) \\
\hline
\end{tabular}


eral weed species (Bais et al., 2003) but at a high dose, it exhibited a phytotoxic effect on lettuce (Golisz et al., 2007). These molecules may mediate the allelopathic activity of buckwheat. However, the artificial culture conditions might have influenced the metabolic processes of the buckwheat seedlings. It is possible that allelochemicals are only released under specific conditions as it is the case for other secondary metabolites. For example, it is clearly established that buckwheat exudates oxalic acid under aluminum stress (Zheng et al., 1998). Its capacity to detoxify aluminum has been associated with highly efficient uptake of phosphate from calcium bound sources (Zhu et al., 2002). In addition to these protective and nutritive functions, oxalic acid may have an allelopathic effect at the rhizosphere scale as it is considered as a low activity allelochemical which could act synergically with other molecules that would enhance its effect (Chaves et al., 2001).

Allelopathic compounds released during decomposition

Aqueous extracts of buckwheat amended soil had an inhibitive effect of $32 \%$ on powell amaranth germination compared to bare soil extracts. But, given that $\mathrm{N}$ concentration, phenolic content and potential presence of other allelochemicals varied between the treatment and the control, this experiment hardly gives conclusive results and the growth inhibition was attributed to N-deficiency (Kumar et al., 2009b). Based on the hypothesis that phytotoxic compounds found in buckwheat tissues may be released into the soil during plant decomposition, several studies focus on assessing the inhibitive effect of buckwheat extracts. Aqueous ethanolic extracts of aerial parts reduced radicle elongation of lettuce by $25 \%$ (Iqbal et al., 2002). Leaves extracts had the highest inhibitive effect on the root elongation of several weeds (Hayashi, 1998; Ohsawa and Nakatani, 2005) followed by shoot and inflorescence extracts (Golisz et al., 2007). During pot bioassays, incorporation of root residues showed no inhibitive effect on the growth of powell amaranth (Kumar et al., 2009b). The analysis of buckwheat extracts from aerial plant parts revealed the presence of several potentially allelopathic compounds (Table 1). The two most important classes are flavonoids and phenolic acids.

The compound that is believed to have the strongest specific total activity is rutin (quercetin-3-O-rutinoside). This is mainly due to its important concentration in the aboveground organs of buckwheat (on average $50.5 \mathrm{mg}$ $\mathrm{g}^{-1}$ DW (Golisz et al., 2007)). Once in the soil however, the disaccharide moiety of rutin may be hydrolyzed to give rhamnose, glucose and quercetin (Kalinova and Vrchotova, 2009) whose specific activity $\left(\mathrm{EC}_{50}\right)$ is approximately 8 times higher than rutin and therefore much less phytotoxic (Golisz et al., 2007). Rutin was found to induce oxidative stress in Arabidopsis (Arabidopsis thaliana) (Golisz et al., 2008), while quercetin was identified as a potent inhibitor of the photosystem II and ATPase of spinach (Spinacia oleracea) (Moreland and Novitzky, 1988). Gallic acid is one of the most phytotoxic compounds found among the phenolic acids of buckwheat. It reduces the root development of lettuce seeds by $50 \%$ at concentrations comprised between 38 and $23 \mathrm{mg}^{-1}$ (Golisz et al., 2007; Kalinova et al., 2007). The mode of action of phenolic allelochemicals has been investigated by biochemical and genetic experiments. When Arabidopsis was exposed to gallic acid, the synthesis of several ROS-related gene products was increased (Golisz et al., 2008). Some phenolic acids, including gallic acid, caused a slight inhibition of phosphate uptake and a depolarization of the membrane potentials of barley (Hordeum vulgare) roots. The intensity of these effects was correlated with the lipid solubility of the tested compounds. Phenolic acids are therefore supposed to act as allelochemicals by altering plant cell membrane properties (Glass, 1973; Glass and Dunlop, 1974). Even though some of the compounds identified in buckwheat are clearly phytotoxic and are serious candidates for an allelopathic role, several points should temper this opinion. First, the phytotoxicity is highly species-dependent. For instance $(+)$-catechin had no significant effect on germination and root elongation of six weed species (Bais et al., 2003) but reduced by half the root elongation of lettuce at $32 \mathrm{ppm}$ (Iqbal et al., 2003). Second the dynamic of the allelochemicals is poorly understood. Once in the soil, some compounds, such as phenolic acids, may be rapidly degraded and lose their bioactivity (Ohno, 2001) or be released progressively and reach an inhibitory level in the soil only after a certain time (Xuan et al., 2005).

\section{CONCLUDING REMARKS}

There is no doubt about the strong suppressive effect against a wide variety of weeds by common buckwheat both in living stands and after residue incorporation. Given the existing literature, it seems very likely that several different suppressive mechanisms coexist. Yet, not all sensitive weed species are susceptible to the same stress factors. However, they are still affected by buckwheat suggesting that the suppressive mechanism can be different between weed species. For the development of weed management strategies using buckwheat, and cover crops in general, it is important to understand how weeds are suppressed by separating and quantifying the underlying factors. This is a demanding challenge as in natural systems these mechanisms co-occur and interact. More research efforts should therefore be put on separating and quantifying the individual suppressive factors in order to assess the suppressive abilities of different cover crops. For instance the role of shading should be precisely quantified as it is frequently considered as one of the major suppressive factors. In our opinion particular attention should also be paid to the differentiation between resource competition and allelopathy because phytotoxic effects and competition for nutrients co-occur and strongly interact in the soil under natural conditions. Moreover the dynamics and the role of released molecules under field conditions should be evaluated in living buckwheat stands as well as after residue incorporation. These findings could provide innovative practical solutions for a better integration of cover crops in crop rotations in order to provide a complementary tool for efficient weed 
management besides the use of herbicides and mechanical weeding.

\section{REFERENCES}

Bais, H. P., Walker, T. S., Kennan, A. J., Stermitz, F. R., Vivanco, J. M. 2003. Structure-dependent phytotoxicity of catechins and other flavonoids: Flavonoid conversions by cell-free protein extracts of Centaurea maculosa (spotted knapweed) roots. J. Agric. Food Chem. 51: 897-901.

Bhowmik, P. C., Inderjit 2003. Challenges and opportunities in implementing allelopathy for natural weed management. Crop Prot. 22: 661-671.

Bicksler, A. J., Masiunas, J. B. 2009. Canada thistle (Cirsium arvense) suppression with buckwheat or sudangrass cover crops and mowing. Weed Technol. 23: 556-563.

Chaves, N., Sosa, T., Alias, J. C., Escudero, J. C. 2001. Identification and effects of interaction phytotoxic compounds from exudate of Cistus ladanifer leaves. J. Chem. Ecol. 27: 611-621.

Creamer, N. G., Baldwin, K. R. 2000. An evaluation of summer cover crops for use in vegetable production systems in North Carolina. Hortscience 35: 600-603.

Eskelsen, S. R., Crabtree, G. D. 1995. The role of allelopathy in buckwheat (Fagopyrum-Sagittatum) inhibition of Canada thistle (Cirsium-Arvense). Weed Sci. 43: 70-74.

Falquet, B., Roux, D., Henriet, L., Tschuy, F., Wirth, J. 2014. Simple method to separate resource competition from allelopathic root interactions. Allelopathy J. 34: 227-240.

Gebhard, C. A., Büchi, L., Liebisch, F., Sinaj, S., Ramseier, H., Charles, R. 2013. Screening de légumineuses pour couverts végétaux: azote et adventices. Recherche Agronomique Suisse 4: 384-393.

Glass, A. D. M. 1973. Influence of phenolic acids on ion uptake. 1. inhibition of phosphate uptake. Plant Physiol. 51: 1037-1041.

Glass, A. D. M., Dunlop, J. 1974. Influence of phenolic acids on ion uptake. IV. depolarization of membrane-potentials. Plant Physiol. 54: 855-858.

Golisz, A., Lata, B., Gawronski, S. W., Fujii, Y. 2007. Specific and total activities of the allelochemicals identified in buckwheat. Weed Biol. Manag. 7: 164-171.

Golisz, A., Sugano, M., Fujii, Y. 2008. Microarray expression profiling of Arabidopsis thaliana L. in response to allelochemicals identified in buckwheat. J. Exp. Bot. 59: 3099-3109.

Hayashi, H. 1998. Effects of leaf and root exudates of common buckwheat on the early growth of weeds. VII international symposium on buckwheat advances in buckwheat research August, Winnipeg, FAGOPYRUM, VII Insects, disease and weeds p 12 .

Iqbal, Z., Hiradate, S., Noda, A., Isojima, S. I., Fujii, Y. 2002. Allelopathy of buckwheat: Assessment of allelopathic potential of extract of aerial parts of buckwheat and identification of fagomine and other related alkaloids as allelochemicals. Weed Biol. Manage. 2: 110-115.

Iqbal, Z., Hiradate, S., Noda, A., Isojima, S. I., Fujii, Y. 2003. Allelopathic activity of buckwheat: isolation and characterization of phenolics. Weed Sci. 51: 657-662.

Kalinova, J. 2004. Influence of common buckwheat on growth of other plant species. International symposium on advances in buckwheat research, August, Prague, Proceedings of the 9th International Symposium on Buckwheat, p. 529.

Kalinova, J., Triska, J., Vrchotova, N. 2005. Biological activity of phenolic compounds present in buckwheat plants. Allelopathy J. 16: 123-129.
Kalinova, J., Vrchotova, N., Triska, J. 2007. Exudation of allelopathic substances in buckwheat (Fagopyrum esculentum Moench). J. Agric. Food Chem. 55: 6453-6459.

Kalinova, J., Vrchotova, N. 2009. Level of catechin, myricetin, quercetin and isoquercitrin in buckwheat (Fagopyrum esculentum Moench), changes of their levels during vegetation and their effect on the growth of selected weeds. J. Agric. Food Chem. 57: 2719-2725.

Kato-Noguchi, H., Sugimoto, H., Yamada, M. 2007. Buckwheat seedlings may inhibit other plant growth by allelopathic substances. Environ. Control Biol. 45: 27-32.

Kaye, J. P., Hart, S. C. 1997. Competition for nitrogen between plants and soil microorganisms. Trends Ecol. Evol. 12: 139143

Khanh, T. D., Chung, M. I., Xuan, T. D., Tawata, S. 2005. The exploitation of crop allelopathy in sustainable agricultural production. J. Agron. Crop Sci. 191: 172-184.

Kumar, V., Brainard, D. C., Bellinder, R. R. 2008. Suppression of powell amaranth (Amaranthus powellii), shepherd's-purse (Capsella bursa-pastoris), and corn chamomile (Anthemis arvensis) by buckwheat residues: Role of nitrogen and fungal pathogens. Weed Sci. 56: 271-280.

Kumar, V., Brainard, D. C., Bellinder, R. R. 2009a. Effects of spring-sown cover crops on establishment and growth of hairy galinsoga (Galinsoga ciliata) and four vegetable crops. Hortscience 44: 730-736.

Kumar, V., Brainard, D. C., Bellinder, R. R. 2009b. Suppression of powell amaranth (Amaranthus powellii) by buckwheat residues: role of allelopathy. Weed Sci. 57: 66-73.

Kumar, V., Brainard, D. C., Bellinder, R. R., Hahn, R. R. 2011. Buckwheat residue effects on emergence and growth of weeds in winter-wheat (Triticum aestivum) cropping systems. Weed Sci. 59: 567-573.

Liebman, M., Davis, A. S. 2000. Integration of soil, crop and weed management in low-external-input farming systems. Weed Res. 40: 27-47.

Moreland, D. E., Novitzky, W. P. 1988 . Interference by flavone and flavonols with chloroplast-mediated electron-transport and phosphorylation. Phytochemistry 27: 3359-3366.

Oerke, E. C. 2006. Crop losses to pests. J. Agric. Sci. 144: 31 $-43$

Ohno, T. 2001. Oxidation of phenolic acid derivatives by soil and its relevance to allelopathic activity. J. Environ. Qual. 30: 1631-1635.

Ohsawa, R., Nakatani, C. 2005. Inter- and intra-cultivar variations in the allelopathic effect of leaf aqueous extract of buckwheat (Fagopyrum esculentum Moench) on the growth of lettuce seedling. Fagopyrum 22: 21-24.

Pervaiz, M. A., Iqbal, M., Shahzad, K., Hassan, A. U. 2009. Effect of mulch on soil physical properties and N, P, K concentration in maize (Zea mays) shoots under two tillage systems. Int. J. Agric. Biol. 11: 119-124.

Rice, E. L. 1984. Allelopathy. Academic Press Inc. (London) Ltd., London.

Teasdale, J. R. 1996. Contribution of cover crops to weed management in sustainable agricultural systems. J. Prod. Agric. 9 475-479.

Teasdale, J. R., Mohler, C. L. 2000. The quantitative relationship between weed emergence and the physical properties of mulches. Weed Sci. 48: 385-392.

Tin, W. W. T., Hayashi, H., Otomatsu, T., Hirose, K., Hasegawa, K., Shigemori, H. 2009. Caprolactam, an inhibitory allelochemical exuded from germinating buckwheat (Fagopyrum esculentum) seeds. Heterocycles 78: 1217-1222.

Tominaga, T., Uezu, T. 1995 . Weed suppresion by buckwheat 6th International Symposium on Buckwheat, August, Shinshu. 


\section{B. FALQUET ET AL.}

current advances in buckwheat research: proceedings of the 6th International Symposium on Buckwheat in Shinshu, p 693.

Tsuzuki, E., Dong, Y. J. 2003. Buckwheat allelopathy: Use in weed management. Allelopathy J. 12: 1-11.

Tsuzuki, E., Yamamoto, Y., Shimizu, T. 1987. Fatty-acids in buckwheat are growth-inhibitors. Ann. Bot. 60: 69-70.

Van Ryswyk, D., Sindel, B. M., Jessop, R., Kristiansen, P. 2004. Effect of night cultivation on the emergence and competition of weeds in buckwheat. 14th Australian Weeds Conference, September, Wagga Wagga. Papers and proceedings: weed management: balancing people, planet, profit, p 312.
Xuan, T. D., Tawata, S., Khanh, T. D., Chung, I. M. 2005. Decomposition of allelopathic plants in soil. J. Agric. Crop Sci. 191: 162-171.

Xuan, T. D., Tsuzuki, E. 2004. Allelopathic plants: Buckwheat (Fagopyrum spp.). Allelopathy J. 13: 137-148.

Zheng, S. J., Ma, J. F., Matsumoto, H. 1998. High aluminum resistance in buckwheat - I. Al-induced specific secretion of oxalic acid from root tips. Plant Physiol. 117: 745-751.

Zhu, Y. G., He, Y. Q., Smith, S. E., Smith, F. A. 2002. Buckwheat (Fagopyrum esculentum Moench) has high capacity to take up phosphorus (P) from a calcium (Ca)-bound source. Plant Soil 239: 1-8. 